\title{
3D Digital Archive of the Burghers of Calais
}

\author{
Daisuke Miyazaki ${ }^{1}$, Mawo Kamakura ${ }^{1}$, Tomoaki Higo ${ }^{1}$, Yasuhide Okamoto ${ }^{1}$, \\ Rei Kawakami ${ }^{1}$, Takaaki Shiratori ${ }^{1}$, Akifumi Ikari ${ }^{1}$, Shintaro Ono ${ }^{1}$, Yoshihiro Sato ${ }^{1}$, \\ Mina Oya ${ }^{2}$, Masayuki Tanaka ${ }^{2}$, Katsushi Ikeuchi ${ }^{1}$, and Masanori Aoyagi ${ }^{2}$ \\ ${ }^{1}$ The University of Tokyo, 4-6-1 Komaba, Meguro-ku, Tokyo 153-8505, Japan \\ \{miyazaki, mawo, higo, okamoto, rei, siratori, ika, onoshin, \\ yoshi, ki\}@cvl.iis.u-tokyo.ac.jp \\ http://www.cvl.iis.u-tokyo.ac.jp/ \\ ${ }^{2}$ National Museum of Western Art, 7-7 Ueno-koen, Taito-ku, Tokyo 110-0007, Japan \\ \{oya, tanaka\}@nmwa.go.jp, msnryg@attglobal.net \\ http: //www.nmwa.go.jp/
}

\begin{abstract}
Auguste Rodin is the most celebrated sculptor of the 19th century. His works, such as The Gates of Hell, The Thinker, and The Burghers of Calais, are famous worldwide. To our knowledge, no art historians have analyzed three-dimensional data of Rodin's work. This paper describes our project to fill this need by digitally archiving the bronze statue, The Burghers of Calais. First, we scanned the geometrical shape of the sculpture by using a laser range sensor. After that, we analyzed the resulting three-dimensional data using expert knowledge in the field of art history and technology developed in the fields of computer vision and graphics.
\end{abstract}

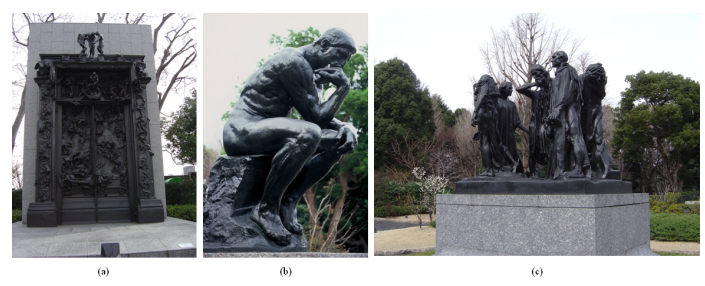

Fig. 1. Rodin's three bronze statues in National Museum of Western Art, Tokyo, Japan: (a) The Gates of Hell, (b) The Thinker, (c) The Burghers of Calais

\section{Introduction}

Historical buildings and cultural assets are subject to the risks of being damaged, destroyed, or ruined by weathering, natural disasters, or man-made disasters. Therefore, it is important to digitally archive these properties [1]. Among archiving methods, three-dimensional (3D) digital archiving [2] is notable for its use of cutting-edge technology. Specifically, 3D digital archiving has significance in the area of information science in two fields: archaeology and information technology.

From the viewpoint of archaeology, permanently preserving the current state of existing cultural assets as digital data is an important subject. Analyzing 3D digital data 
by computers provides new aspects for research in archaeology and art history. Moreover, there is a societal advantage: any number of people can examine computergenerated images of these cultural assets, seeing different colors and more viewpoints than are possible to observe in the real world.

From the viewpoint of information science, digitally archiving cultural assets provides a strong motivation to promote the development of information technology, since the preservation of cultural assets is important both nationally and worldwide. The technology of measurement is also promoted by this subject since obtaining archive data requires special sensors that capture the complex shapes and colors of cultural assets. Also, developing software to process or show the immense amount of data typical of large-sized cultural assets provides a frontier that must be crossed by new and creative methods.

To what fields should we apply these new methods? Until now, many sites, architectures, and statues have been three-dimensionally archived. Previous works have been largely directed to rock- and stone-like objects, but we believe that these methods might be successfully applied to bronze statues. To test this theory, we have attempted to capture 3D data for certain sculptures created by the most famous sculptor of the 19th century, François-Auguste-René Rodin [3].

Rodin's best-known works include The Gates of Hell, The Thinker, and The Burghers of Calais (Fig. 1). Among these, The Burghers of Calais (subsequently referred to as The Burghers) is a sculpture commissioned by the city of Calais, France. The work is based on the historical fact that six citizens of Calais volunteered to sacrifice their lives to England's Edward III in 1347 to save the lives of their fellow citizens. The city wanted the statue placed on a lofty pedestal, showing high-blown fortitude and courage. Instead, Rodin placed the group near ground level, where they were more accessible to viewers, and showed the men exhibiting the sullen, worn, and even fearful expressions of bare human emotion. Rodin first made plaster casts of the figures, and from these plaster casts bronze statues were made. Among Japanese public organizations, the National Museum of Western Art owns The Burghers as a group of bronze sculptures, and eleven more works exist in other place in the world. It is usual to create multiple bronze statues from same cast; however, The Burghers is unusual in that the same cast was used in two different parts in The Burghers, even though those parts are of different people.

We obtained a 3D digital model of the approximately 2-m tall The Burghers in the National Museum of Western Art using a 3D digital archiving technique. We generated an image from an upper view which is difficult to achieve for a real statue, generated an image of a plaster figure which Rodin first made, and compared the similarity of two parts from the statue which are believed to be made from same cast. This paper is therefore organized as follows: In Section 2, we present our procedure to create a 3D model. In Section 3, some analyses and discussions of this work from the standpoint of art history are presented. In Section 4, we discuss the Museum displays of our images generated from the 3D model, and the reactions of museum visitors. In Section 5, we conclude that art historians are correct: certain casts were indeed reused within the group. 


\section{3D Digital Archive}

3D digital archiving is achieved by a laser range sensor, which measures the surface shape of the object in high precision (Fig. 2) [4]. The process to obtain the shape of the object can be divided into three steps: scanning, alignment, and merging. We will explain these three steps in this section.

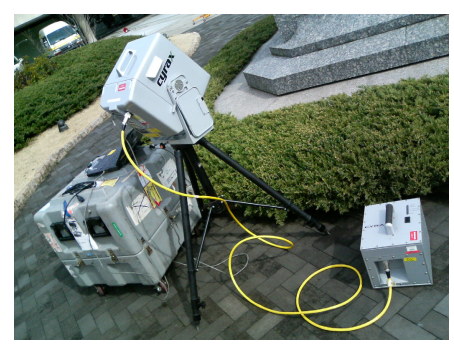

Fig. 2. Laser range sensor

\subsection{Measurement (Scanning)}

The field of view of the laser range sensor is limited; thus, the sensor only obtains a partial shape of the object during each scan. To generate a 3D model of the object, we need to measure the partial 3D data many times from different positions and directions (Fig. 3) and correlate the data.

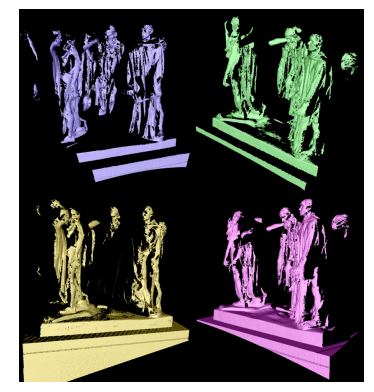

Fig. 3. Obtained data

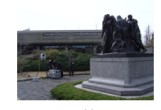

(a)
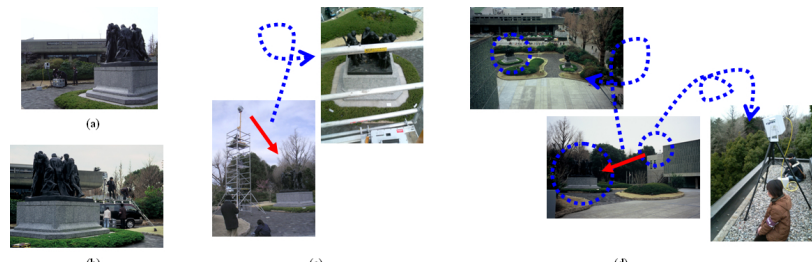

Fig. 4. Scanning from different position: (a) From ground, (b) from car, (c) from scaffold, (d) from roof 
The Burghers is kept outdoors; it is outside the National Museum of Western Art. We scanned the statue from ground level, from a parked car, from a scaffold, and from the roof of the museum building (Fig. 4).

\subsection{Registration (Alignment)}

Each of the partial 3D models obtained by a laser range sensor has different coordinate systems depending on the position and the direction of the sensor. Therefore, we have to align these partial models in order to represent the data in a unified coordinate system.

Iterative Closest Point (ICP) algorithm [5] is often used for estimating the relative position between two overlapped models. This method first search for a pair of corresponding points between two models, and then estimate the relative position between two models such that the total squared distance for all pairs of corresponding points is minimized. The solution is obtained when this iterative process converges.

If we sequentially align each pair of partial models, the models do not align well due to accumulation errors. To avoid this problem, we apply a method which simultaneously estimates the relative position for all partial models (Fig. 5) [6].

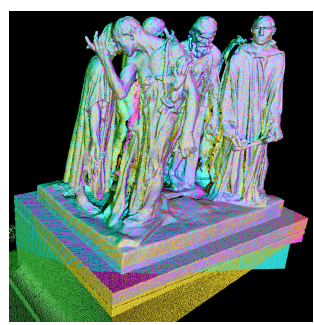

Fig. 5. Aligned data

\subsection{Integration (Merging)}

Aligned data have overlapping regions; thus, we have to merge all partial models into one integrated model.

One of the merging algorithms is the Volumetric method [7,8]. It first projects all partial models into a voxel space, and then extracts the surface model from the voxel space where the signed distance field becomes zero. The extracted volumetric data are then converted into mesh data by using the Marching Cubes method [9]. In our work, we used Sagawa's method, which is based on the Volumetric method, for merging the data (Fig. 6) [10].

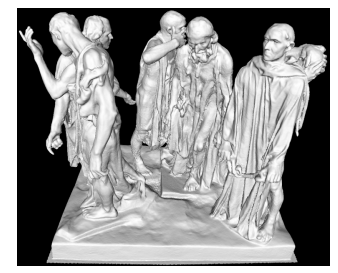

Fig. 6. Merged data 


\section{Analyses from the Aspect of Art History}

3D digital model obtained from laser range sensor has many advantages such as the fact that we can inspect the object from arbitrary viewpoints, we can change the surface material virtually, and we can produce images with different illuminations. In this section, we analyze and represent the 3D digital data from the aspect of art history.

\subsection{Arbitrary Viewpoint}

Since we have the whole shape as a digital data set, we can choose arbitrary viewpoints. It is said that Rodin struggled to find the best position in which to settle the statue; that he considered carefully how it looked when seen by viewers. By changing the viewpoint of the $3 \mathrm{D}$ digital model, we can look at the statue not only horizontally, but also from the bottom or the top (Fig. 7).

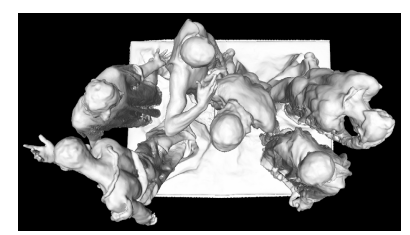

Fig. 7. Rendered image of an upper view

\subsection{Rearrangement}

Editing the shape of the 3D digital model is undoubtedly easier than changing the shape of a real object. Rodin tried to express the movement of the human body in static statues by this group of sculptures and its arrangement of six heroes. Figure 8 demonstrates the image of the six people rearranged into a line, by cutting each statue away from the others. The figure clearly shows their individual facial expressions and the inclinations of their bodies, which can be difficult to recognize when seeing them as a group.

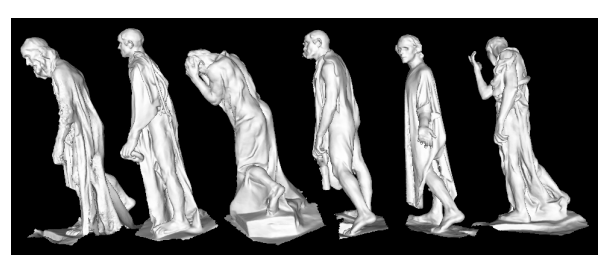

Fig. 8. Rendered image of lining up the group's six individuals

\subsection{Candle Light}

It is easy to change the illumination and generate synthetic shadowing when a 3D digital model is available. Like all of Rodin's work, the bronze statue of The Burghers 
is widely exhibited and compared with its plaster model. However, Rodin preferred to look at his white plaster model when it was lit by candlelight. Figure 9 is an image of the white plaster model lit by candlelight, which is reproduced from $3 \mathrm{D}$ digital model.

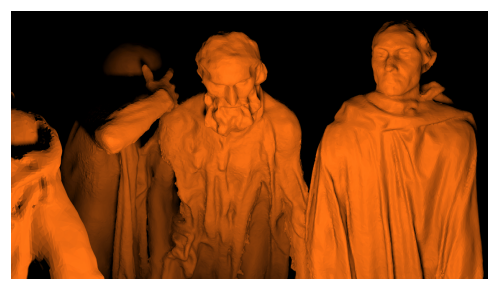

Fig. 9. Rendered image of white plaster figures lit by candlelight

\subsection{Different Environment}

It is easy to create an image in different synthetic environments using a $3 \mathrm{D}$ digital model. The Burghers are located in different parts of the world, and people can find them in many situations. We can reproduce these situations with computer graphics. Figure 10 shows some images of the bronze sculptures reproduced from the 3D digital model under different illumination distributions. The reflection property of the bronze material to render these images is set manually. Illumination distribution data are obtained from a web site [11]. We can see how The Burghers look if they are situated in a different place.
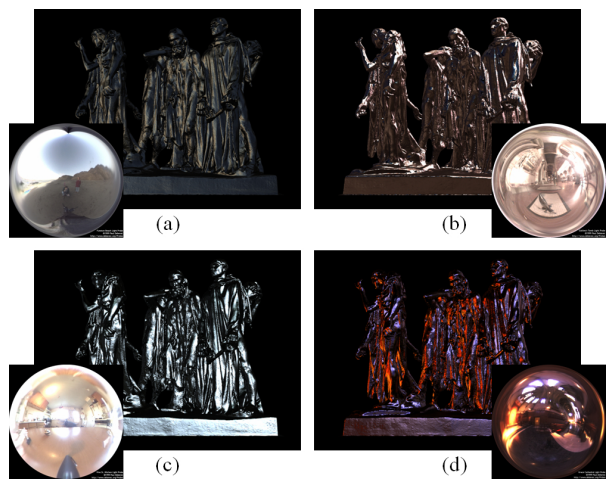

Fig. 10. Rendered images of bronze sculptures under different environments: (a) Funston Beach at Sunset, (b) Galileo's Tomb, Santa Croce, Florence, (c) Kitchen at 2213 Vine St, (d) Grace Cathedral, San Francisco

\subsection{Same Motif}

It is said that Rodin created many kinds of casts of human parts such as heads and hands, and created many works by combining these parts. Art historians say that two hands of different persons in The Burghers are produced by the same cast. To verify this historical fact, first we cut out two hands which are said to be made from the 
same cast, and then we aligned these two shapes by using our alignment algorithm. We obtained convincing evidence that these two hands were created from same cast (Fig. 11).

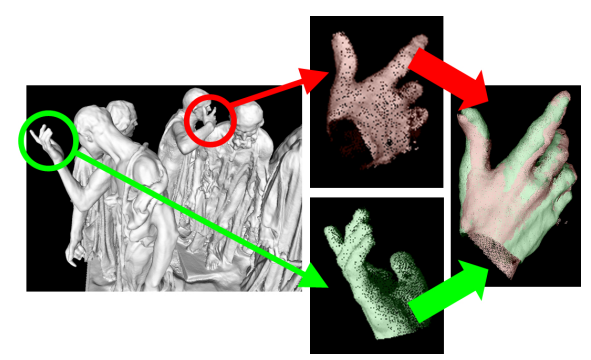

Fig. 11. The result of aligning the two hands created from same cast

\section{Demonstrations Using Mobile Computer}

From April 29th, 2006 to May 7th, 2006, we demonstrated our computer graphic animations to people who visited the National Museum of Western Art. An audio guide is often used in museums to help people understand the exhibits more deeply; we went one step further and provided a video guide. This video guide, which included our computer animations, was produced by the Japan Broadcasting Corporation [12]. It ran on a mobile computer developed by the YRP Ubiquitous Networking Laboratory (head manager: Prof. Ken Sakamura of The University of Tokyo) [13].

\subsection{Opinions from Visitors}

After each demonstration, we asked each visitor to complete a questionnaire. Fig. 12 is the answer to their overall satisfaction with our computer graphic animations. $44 \%$ of the visitors expressed a favorable answer while only $13 \%$ expressed an unsatisfied feeling.

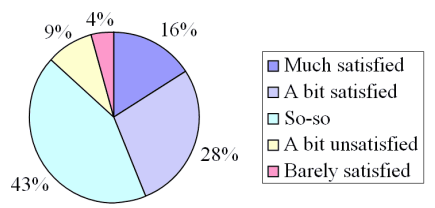

Fig. 12. The answer to the question, "Were you satisfied with the computer graphic animation?"

We demonstrated the animations of the candlelight scene (Fig. 9), the upper view scene (Fig. 7), and the lining-up scene (Fig. 8). We asked visitors whether or not they felt that the animations were realistic, and also whether they were interesting. The answer is shown in Fig. 13. Some people did not recognize the candlelight scene as being computer graphics, possibly due to the illumination effects of candlelight. We believe that if we do not add any illumination effects to our computer graphics, we cannot achieve realism. 


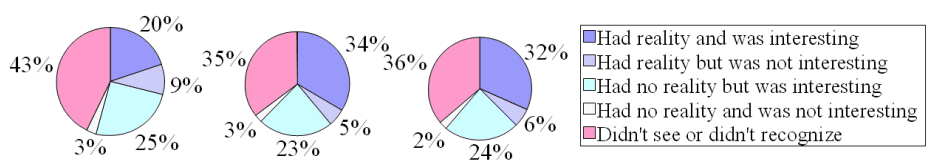

(a)

(b)

(c)

Fig. 13. The answer to the question, "Were you satisfied with the computer graphic animations of (a) the candlelight scene, (b) the upper view scene, and (c) the lining up scene?"

Fig. 14 shows that there is a gender difference between men and women in these responses. The question is that of Fig. 12, "Were you satisfied with the computer graphic animations?" Women, interestingly, felt that the simulations were more realistic than did men. Also, some women did not recognize the video as computer graphics due to its high degree of realism. We speculate that women tend to accept new ideas, and quickly accept the look and feel of our computer graphics as being reality. We further speculate that, on the other hand, because men are well-acquainted with computer graphics through movies or video games -- more so than women -- they only perceive realism when computer graphics are of very high quality.

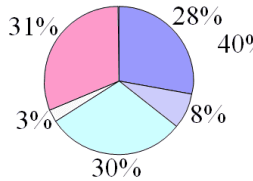

(a)

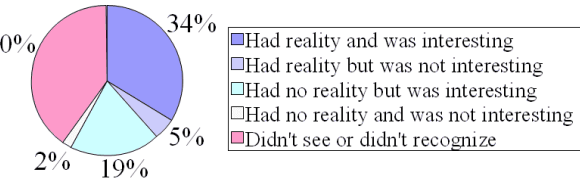

(b)

Fig. 14. The answer to the question, "Were you satisfied with the computer graphic animations?", from (a) men and (b) women

\section{Conclusions}

We have created a 3D digital model of a bronze statue, The Burghers of Calais, sculpted by the most famous sculptor of the 19th century, Auguste Rodin, who is also famous for his works, The Gates of Hell and The Thinker. First, we scanned the sculpture by laser range sensor from different positions and directions; then, we aligned all our valid datasets of vertices and merged these datasets into a 3D digital model. After that, we created computer graphic animations and demonstrated these animations using a mobile computer to the visitors of the Museum. Our animations produced many favourable visitor impressions.

We also presented a result of the comparison between the hands of two different figures in The Burghers. From this result, we concluded that these two hands were indeed made from the same cast, thus proving assertions previously made by art historians.

All these analyses could not have been carried out unless a 3D digital model had been developed. This work therefore yielded especially valuable information because of collaboration between computer scientists and art historians. 


\section{Acknowledgements}

Our development of a 3D digital archiving technique was supported in part by the Ministry of Education, Culture, Sports, Science and Technology under the Leading Project: Development of High Fidelity Digitization Software for Large-Scale and Intangible Cultural Assets. 3D measurement of The Burghers of Calais was performed as a part of the Wel.com Museum Project [14]. The Wel.com Museum Project was conducted by the National Museum of Western Art and its director Masanori Aoyagi, as well as Prof. Ken Sakamura of The University of Tokyo, Prof. Katsushi Ikeuchi of The University of Tokyo, Nissha Printing Co., Ltd., YRP Ubiquitous Networking Laboratory, and NHK Educational Corporation. The authors thank Kyoko Kuramori and Kenji Yokoo of Japan Broadcasting Corporation, and Hisato Arai of the National Museum of Western Art for their great help. The authors thank Joan Knapp and Robert Knapp for proofreading and editing this manuscript.

\section{References}

1. UNESCO Archives Portal, http://www.unesco.org/webworld/portal_archives/

2. K. Ikeuchi and Y. Sato, Modeling from Reality, Kluwer Academic, Boston, 2001.

3. Musée Rodin, The Complete Guide to Rodin, Tankosha, Kyoto, Japan, 2005. (in Japanese)

4. Cyrax 2500, http://www.leica-geosystems.com/

5. P. Besl and N. McKay, "A Method for Registration of 3-D Shapes," IEEE Trans. On Pattern Analysis and Machine Intelligence, 14(2), 239-256, 1992.

6. T. Oishi, A. Nakazawa, R. Kurazume, and K. Ikeuchi, "Fast Simultaneous Alignment of Multiple Range Images using Index Images," Proc. Int'1 Conf. on 3-D Digital Imaging and Modeling, 476-483, 2005.

7. B. Curless and M. Levoy, "A Volumetric Method for Building Complex Models from Range Images," Proc. SIGGRAPH, 303-312, 1996.

8. M. Wheeler, Y. Sato, and K. Ikeuchi, "Consensus surfaces for modelling 3D objects from multiple range images," Proc. Int'l Conf. on Computer Vision, 917-924, 1998.

9. W. Lorensen and H. Cline, "Marching cubes: a high resolution 3d surface construction algorithm," Proc. SIGGRAPH, 163-170, 1987.

10. R. Sagawa, K. Nishino, and K. Ikeuchi, "Adaptively Merging Large-Scale Range Data with Reflectance Properties," IEEE Trans. on Pattern Analysis and Machine Intelligence, 27(3), 392-405, 2005.

11. Light Probe Image Gallery, http://www.debevec.org/Probes/

12. Japan Broadcasting Corporation, http://www.nhk.or.jp/

13. YRP Ubiquitous Networking Laboratory, http://www.ubin.jp/

14. Wel.com Museum Project, http://www.nmwa.go.jp/jp/files/wel.pdf (in Japanese) 